\title{
Comment on "Status of the reference X-ray powder diffraction patterns for the serpentine minerals in the PDF database-1997," by Fred J. Wicks [Powder Diffr. 15, 42-50 (2000)]
}

As Chairman of the Minerals Subcommittee of the International Centre for Diffraction Data (ICDD) for the past four years, I read with great interest the recent article by Fred Wicks, "Status of the reference X-ray powder diffraction patterns for the serpentine minerals in the PDF database1997." The detailed discussion of the problems and complexities associated with powder diffraction analyses of this important group of minerals is a valuable service to the diffraction community and will certainly result in a much improved PDF database. It is appropriate that the ICDD Grantin-Aid program provided some of the support for the serpentine project, and the PDF editors at ICDD Headquarters look forward to receiving from Dr. Wicks the improved powder diffraction standard patterns described in the article.

Reading through the paper, I detected a sense of frustration from the author that there were so many problems with the serpentine minerals PDF entries. And in fact, I share that frustration, not only with the serpentine minerals but with many other complex mineral groups. It is important to remember, however, that the principal way in which problems in the PDF are fixed is through contributions of high quality data by experts such as Dr. Wicks. The ICDD is a not-forprofit, largely volunteer organization whose single goal is to build and maintain an accurate powder diffraction database for the international science community. In general, the members of ICDD, and the PDF users, are also the major contributors to the database. All of us rely upon other PDF users to provide stewardship for the database entries relating to materials for which they have an expertise. So, I strongly encourage other scientists to conduct studies/critiques, similar to that done by Dr. Wicks on the serpentine minerals, of PDF entries for materials with which they are familiar. The ICDD welcomes all input for the purpose of improving the PDF, particularly in the form of new and improved diffraction data.

Jeffrey E. Post

Curator, National Gem and Mineral Collection

Smithsonian Institution

Washington, DC 20560-0119 